\title{
Adoption of Recommended Practices Disseminated through Agricultural Polyclinics
}

\author{
S. G. Puri", S. D. Wangikar and P. S. Kapse \\ Agricultural Technology Information Centre, VNMKV, Parbhani-431402 (MS), India \\ Department of Extension Education, Vasantrao Naik Marathwada Krishi Vidyapeeth, \\ Parbhani (MS), India \\ *Corresponding author
}

\section{A B S T R A C T}

\section{Keywords}

Beneficiaries of

Agricultural

Polyclinics,

Adoption,

Relationship

Article Info

Accepted:

12 September 2019

Available Online:

10 October 2019
The present study was conducted in Parbhani, Nanded and Osmanabad districts of Maharashtra state with specific objectives; to study the extent of adoption of recommended practices disseminated through Agricultural Polyclinics among the respondents. Total 150 beneficiary respondents were interviewed for the study. It was observed that majority of the respondents (65.34 \%) had medium level of overall adoption. Out of fifteen recommended extension activities / practices extended through Agricultural Polyclinic, only one activity i.e. utilization of their possessed land for cultivation was adopted by all the respondents. Other seven Agricultural Polyclinic activities / practices were adopted by majority of the respondents. The variables namely benefits availed, knowledge, risk orientation, annual income, economic motivation, land holding, education, attitude, extension contact and social participation were positively and significantly related with adoption of activities/practices extended through Agricultural Polyclinics.

\section{Introduction}

In the national perspective, agriculture should develop into an effective instrument for creating income, employment and food availability. These triple goals could be achieved if we generate and disseminate the agricultural technologies that are relevant to the end users. Farming is largely depends upon vagaries of monsoon in Maharashtra. The most outstanding feature of agriculture in Maharashtra is the large semi-arid tropics area with erratic rains causing dwindling in the production, most often small landholders, who constitute large majority, are worst affected during adverse monsoon. Mitigating such 
situation and increasing yield per hectare implies the shift from traditional methods of production to new scientific methods that include new technological components such as, new varieties, cultural practices and new farming system.

Technology development and technology transfer are the two crucial processes in agricultural development and socio-economic upliftment of the farming community.

There is a large section of farming community, which is still unaware of technological development in the field of agriculture in Maharashtra state. In order to able to compete, farmers should not only be well informed about findings of agricultural research, which are relevant for their situation, but they should also learn from practical experience through training and demonstration.

In this regard, the government of Maharashtra has launched a pilot programme-"Agricultural Polyclinic" in 1997-98 as the innovative institutions for narrow down the gap between research and its actual application by imparting vocational farmers training, production technology demonstration and agricultural services (diagnostics) to farmers.

This is the programme for farmers to be able to increase their adoption level for maximise the productivity and production of farming. Keeping this in view, the present investigation was undertaken with the specific objectives.

To study the extent of adoption of recommended practices disseminated through Agricultural Polyclinics by the respondents.

To find out the relationship between profiles of respondents with adoption of recommended practices disseminated through Agricultural Polyclinic.

\section{Materials and Methods}

The present study was conducted in three districts namely, Parbhani, Nanded and Osmanabad of Maharashtra State. Two talukas were selected on the basis of earlier establishment of Agricultural Polyclinics and two Agricultural Polyclinics from each district were selected on the basis of same principle.

Twenty five (25) respondents were drawn by $\mathrm{n}^{\text {th }}$ method of random sampling from each Agricultural Polyclinics with the help of beneficiaries list of Agricultural Polyclinics. Thus, final sample comprised of 150 respondents.

The extent of adoption of the recommended activities / practices concerning Agricultural Polyclinic was measured by means of adoption index, developed on the lines of adoption intensity index used by Choubay (1972).

Fifteen technological practices were selected for the study of extent of adoption. The proportions for each of the fifteen practices (actual/potential) were calculated and multiplied by the corresponding weightage.

The values of all the fifteen items were summed and then divided by 45 , the total number of weightage.

The resulting value was multiplied by 100 to indicate the percentage of the extent of adoption of practices extended through Agricultural Polyclinic. The resulting value was taken as 'adoption index'

Adoption index

Practices actual used

Practices recommended
or potential to be used




\section{Results and Discussion}

\section{Adoption of recommended practices disseminated through Agricultural Polyclinic among the respondents}

The adoption level of the respondents in relation to disseminated practices / activities was assessed and findings are presented Table 1 and 2.

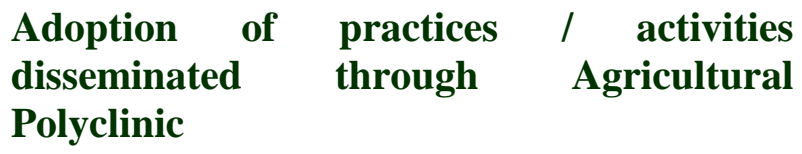

The data regarding adoption of different practices/activities extended through Agricultural Polyclinic by the respondents are illustrated in Table 1.

Table 1 revealed that cent per cent respondents were utilizing their possessed land for cultivation. Other practices adopted by majority of the respondents were insect / pests diagnostic facilities $(97.33 \%)$, improved implements (96.66\%), Nadep compost $(92.66 \%)$ and Neemark $(92.00 \%)$.

Further, it was noted that equal $(90.00 \%)$ of the respondents had adopted soil testing practice and contour development technology. Vermicompost utilization activity was adopted by 87.33 per cent of the respondents.

Further, it was noticed that nearly half $(47.33 \%)$ of the respondents had adopted use of HaNPV technology, whereas 44.00 per cent of the respondents had adopted the seed germination testing technology, while significant $(36.00 \%, 33.33 \%, 30.66 \%$ and $26.66 \%$ ) had adopted Trichocard, improved irrigation systems, farm pond and cold storage (zero energy), respectively. Meagre percentage of the respondents $(4.00 \%)$ had adopted high tech agricultural technology based on shadenet and green house.

Overall adoption level of recommended practices / activities disseminated through Agricultural Polyclinic

The data pertaining to overall adoption level of practices /activities disseminated through Agricultural Polyclinic by the respondents are given in Table 2.

So far as distribution of the respondents on the basis of overall extent of adoption of activities/ practices extended through Agricultural Polyclinic was concerned, it is visible from Table 2 that majority of the respondents $(65.34 \%)$ had medium level of adoption, followed by 21.33 per cent and 13.33 per cent respondents had high level and low level of adoption, respectively.

Looking to the importance of the Agricultural Polyclinic activities/practices from the point of view of increasing the crop production, decreasing expenditure, proper utilization of available resources and inputs, the adoption receives a boost and the beneficiaries were seen to be motivated to adopt Agricultural Polyclinic activities/practices.

Relationship between profile of the respondents with adoption of activities/practices disseminated through Agricultural Polyclinic

Data pertaining to the relationship between personal, socio economic and psychological characteristics of the respondents and adoption of activities/ practices disseminated through Agricultural Polyclinic are presented in Table 3. 
Table.1 Distribution of the respondents by adoption of practices / activities of Agricultural Polyclinic

\begin{tabular}{|c|c|c|c|c|c|}
\hline \multirow{2}{*}{$\begin{array}{c}\text { Sr. } \\
\text { No. }\end{array}$} & Practices/Activities & \multicolumn{2}{|c|}{ Adoption } & \multicolumn{2}{c|}{ Non adoption } \\
\hline 1 & Frequency & Percent & Frequency & Percent \\
\hline 2 & Land Utilization of possessed & 150 & 100.00 & 00 & 00.00 \\
\hline 3 & Contour development & 135 & 90.00 & 15 & 10.00 \\
\hline 4 & Farm pond preparation & 46 & 30.66 & 104 & 69.34 \\
\hline & Use of improved irrigation & 50 & 33.33 & 100 & 66.67 \\
\hline 5 & systems & & & & \\
\hline 6 & Nadep compost utilization & 139 & 92.66 & 11 & 7.34 \\
\hline 7 & Vermicompost utilization & 131 & 87.33 & 19 & 12.67 \\
\hline 8 & $\begin{array}{c}\text { Insect/pests diagnostic facilities } \\
\text { utilization }\end{array}$ & 146 & 97.33 & 04 & 2.67 \\
\hline 9 & Use of HaNPV & 71 & 47.33 & 79 & 52.67 \\
\hline 10 & Use of Trichocard & 54 & 36.00 & 96 & 64.00 \\
\hline 11 & Use of Neemark & 138 & 92.00 & 12 & 8.00 \\
\hline 12 & Soil testing & 135 & 90.00 & 15 & 10.00 \\
\hline & $\begin{array}{c}\text { Utilization of improved } \\
\text { implements }\end{array}$ & 145 & 96.66 & 05 & 3.34 \\
\hline 13 & $\begin{array}{c}\text { Use of cold storage (zero } \\
\text { energy) }\end{array}$ & 40 & 26.66 & 110 & 73.34 \\
\hline 14 & Use of shade net \& green house & 06 & 04.00 & 144 & 96.00 \\
\hline 15 & $\begin{array}{c}\text { Use of seed germination testing } \\
\text { lab }\end{array}$ & 66 & 44.00 & 84 & 56.00 \\
\hline
\end{tabular}

Table.2 Distribution of the respondents by level of Adoption of activities/ practices disseminated through Agricultural Polyclinic

\begin{tabular}{|c|c|c|c|}
\hline Sr.No. & Category & Frequency & Per cent \\
\hline $\mathbf{1 .}$ & Low (score below 35.00) & 20 & $\mathbf{1 3 . 3 3}$ \\
\hline $\mathbf{2 .}$ & Medium (score 35.01 to 63.69) & 98 & $\mathbf{6 5 . 3 4}$ \\
\hline $\mathbf{3 .}$ & High (score 63.70 and above) & 32 & $\mathbf{2 1 . 3 3}$ \\
\hline & Total & 150 & $\mathbf{1 0 0 . 0 0}$ \\
\hline & Mean & & $\mathbf{4 9 . 3 5}$ \\
\hline
\end{tabular}


Table.3 Relationship of profile of the respondents with adoption of activities / practices disseminated through Agricultural Polyclinic

\begin{tabular}{|c|c|c|}
\hline Sr. No. & Profile / Characteristics of the respondents & Correlation coefficient \\
\hline 1 & Age & 0.042 \\
\hline 2 & Education & $0.465 *$ \\
\hline 3 & Occupation & -0.058 \\
\hline 4 & Land holding & $0.494 *$ \\
\hline 5 & Annual income & $0.547 * *$ \\
\hline 6 & Social participation & $0.285 * *$ \\
\hline 7 & Extension contact & $0.358^{* *}$ \\
\hline 8 & Risk orientation & $0.552 * *$ \\
\hline 9 & Economic motivation & $0.500 * *$ \\
\hline 10 & Attitude & $0.415 * *$ \\
\hline 11 & Knowledge & $0.830 * *$ \\
\hline 12 & Benefits availed & $0.833 * *$ \\
\hline
\end{tabular}

** Significant at 0.01 level of probability

The results of correlation analysis showed from Table 3 that out of 12 variables, benefits availed, knowledge, risk orientation, annual income, economic motivation, land holding, education, attitude, extension contact and social participation, were positively and significantly related with adoption of activities/practices at 0.01 per cent level of probability. Whereas age and occupation could not show any relationship with adoption of Agricultural Polyclinic activities/ practices.

These findings are in line with the findings of Mohammad et al., (2004), Prakash and Brar (2006), Halakatti et al., (2007) and Meenal and Rajan (2007).

From the above findings, it can be concluded that out of fifteen recommended extension activities / practices disseminated through Agricultural Polyclinic, only one activity i.e. utilization of possessed land for cultivation was adopted by all the respondents. Other seven activities/practices, namely insect/pests diagnostic facilities, improved implements, Nadep compost, Neemark, soil testing practice, contour development technology and
Vermicompost were adopted by more than three-fourth of the respondents. Remaining six activities/practices namely HaNPV, seed germination testing, Trichocard, improved irrigation systems, farm pond preparation and facility of cold storage (zero energy) were adopted by less than half of the respondents. Meagre proportion of the respondents adopted high tech agricultural technology based on shade net and green house. It was seen that majority of the respondents had medium level of overall adoption.

The variables namely benefits availed, knowledge, risk orientation, annual income, economic motivation, land holding, education, attitude, extension contact and social participation were positively and significantly related with adoption of activities/practices extended through Agricultural Polyclinics.

\section{References}

Choubay, C.L. 1972. A study of differential adoption of high yielding wheat varieties technology as related to and influenced by selected demographic, 
socio-psychological and political variables in Sehore district, Madhya Pradesh. Ph.D. Thesis, IARI, New Delhi.

Halakatti, S.V., Kamareddy, V. and Gowada, S.M. 2007. Determinants of adoption of dairy farming technologies by rural women under SGSY scheme. Karnataka J. Agric. Sci., 20(2):323325.

Meenal, R. and Rajan, R.K. 2007. Impact of socio-economic characters of sericulturists on knowledge, adoption and cocoon production in Tamilnadu. Indian J. Seric., 46(1):49-51.
Mohammad Ajaz-ul-Islam, Masoodi, N.A. and Masoodi, T.H. 2004. Knowledge and adoption of Agroforstry practices among farmers in North Kashmir. Asian J. Extn. Educ., 23(2):46-51.

Prakash, A. and Brar, D.S. 2006. Knowledge and adoption level of farmers of Haryana under Crossbreeding Programme. Indian J. Exten. Edun., 1(1):16-18.

Tapre, S.A. and Ingle, P.O. 2004. Evaluation of Beekeeping Vocation. Indian J. Exten. Edun., 40(1\&2):138-140.

\section{How to cite this article:}

Puri, S. G., S. D. Wangikar and Kapse, P. S. 2019. Adoption of Recommended Practices Disseminated through Agricultural Polyclinics. Int.J.Curr.Microbiol.App.Sci. 8(10): 13941399. doi: https://doi.org/10.20546/ijcmas.2019.810.163 